Journal of Teacher Education for Sustainability, vol. 17, no. 1, pp. 58-71, 2015

\title{
Knowledge, Attitudes and Behaviour regarding Waste Management in a Grammar and a Comprehensive School in England - Results from a School Questionnaire
}

\author{
Karin Dorina Kolbe \\ University of Koblenz and Landau, Germany
}

\begin{abstract}
Well-organised waste management is an essential part of sustainable development. The saving of resources and energy is everyone's concern and environmental education is vital to guarantee a sustainable lifestyle in the long run. To find out what similarities and differences in views regarding waste management exist between grammar school pupils and comprehensive school pupils in England, questionnaires were designed and distributed in two schools in the same English city. The questionnaires aimed at quantifying and establishing students' knowledge, attitudes and behaviour regarding waste management. The results illustrate that students from the grammar school had higher levels of knowledge, were more likely to recycle and used more sources of information regarding waste management. Waste reduction was considered important by almost all students. However, students in both schools considered composting and waste reduction as less important than recycling and thereby did not fully agree with sustainable waste management.
\end{abstract}

Keywords: waste management, education for sustainable development, selective education, sustainable development, environmental education, waste management, waste hierarchy

Effective and efficient waste management is an essential part of sustainable development (Baud, Grafakos, Hordijk, \& Post, 2001; Morrissey \& Browne, 2004). At the level of the European Union (EU), a range of strategies to deal with waste are suggested (European Commission (EC), 1996, 2011; Pires, Martinho, \& Chang, 2011; Wilson, 1996). On the societal level, education about environmental matters is vital to help achieve a more sustainable lifestyle in the long run. Primary and secondary school tuition has been identified as a key factor regarding education in general and environmental education in particular (Ballantyne, Fien, \& Packer, 2001; Gross, 1977; Farmer, Knapp, \& Benton, 2007). To address the particular needs of different student groups, it is essential to understand what levels of knowledge already exist in these student popu- 
lations. Until now, grammar school and comprehensive school pupils have never been compared with respect to their knowledge, attitudes and behaviour regarding waste management. To find out what differences exist, questionnaires regarding waste management were distributed to students in a grammar school and a comprehensive school in the same city in eastern England. The questionnaire was designed to assess students' knowledge, the perception which they held of different waste management options and their behaviour regarding recycling, as well as their attitudes towards waste reduction.

While some grammar schools have a long history, grammar schools that are in existence today in England and Wales are largely a product of the 1840 Grammar School Act (Gordon \& Lawton, 2003; Oakland, 1993). A selection process at the age of eleven leads to students entering grammar school, who are believed to be more able than their counterparts in comprehensive schools. Admission to the grammar school depends on an academic selection test, such as the eleven plus. The eleven-plus tests arithmetic, writing and general problem solving abilities of the students. It does not cover environmental education or waste management specifically.

There has been a long debate on whether this system is useful for the individual students and society as a whole (Boliver \& Swift, 2011; Clifford \& Heath, 1984; Sullivan, Parsons, Wiggins, Heath, \& Green, 2014). Supporters of selective education argue that it is more equitable because it selects students based upon their academic achievements instead of social class or economic power, although this hypothesis has been challenged by some researchers (Harris \& Rose, 2013; Iannelli, 2013; Steedman, 2012; Walford, 1994). Also, it is believed that a stimulating learning environment is created by tutoring the stronger and weaker students in separate groups (Manning \& Pischke, 2006). Critics, on the other hand, point out that educational equality decreased rather than increased as a result of selective education (Hanushek \& Woessmann, 2006). Moreover, it is pointed out that a selection process at the age of eleven is too early for many children because many cognitive developments happen after this age (Manning \& Pischke, 2006). Overall, grammar schools are more socially exclusive (Ball, Bowe, \& Gewirtz, 1996; Crozier, Reay, James, Jamieson, Beedell, Hollingworth, \& Williams, 2008; the Sutton Trust, 2005). The proportion of students with an Asian background is higher than in the general population, black students as well as students from poorer backgrounds are underrepresented (Cribb, Jesson, Sibieta, Skipp, \& Vignoles, 2013). Differences between the two school types might therefore be a result not only of the different institutional backgrounds, but also of social exclusiveness. However, this must not hide the fact that knowledge of potential differences - no matter for which reasons they exist - is important. Teachers and legislators need to be aware of the different perceptions and knowledge levels to provide suitable approaches regarding education about sustainable development.

\section{The EU Waste Hierarchy}

In 2008, the EU waste hierarchy, which can be seen in Figure 1, became legally binding for EU member countries (EC, 2012). Its aims are the prevention of waste, the saving of energy and the conserving of resources (Schmidt, Holm, Merrild, \& Christensen, 2007). According to the waste hierarchy, the best option regarding waste management is to avoid the production of waste in the first place. If this is not possible, waste should 
be re-used since this will save a maximum of resources and energy. If neither reduction nor re-use is possible, waste materials should be recycled, composted, treated via incineration with energy recovery or - if all of these options are not possible - landfilled (European Parliament and European Council, 2008).

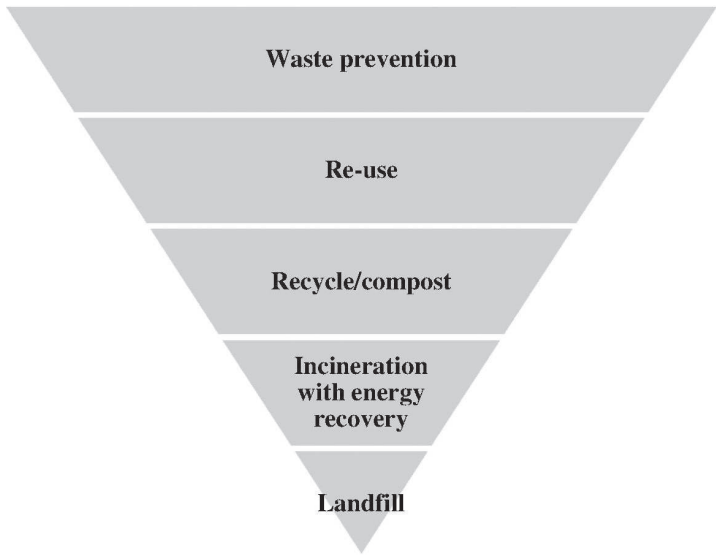

Figure 1. The waste hierarchy as described in the EU Waste Framework Directive.

\section{Waste Management in the United Kingdom}

In the past, a large proportion of the UK's household waste was disposed of in landfill sites. In 2003, the UK landfilled $438 \mathrm{~kg}$ of municipal waste per capita $-74 \%$ of its total waste (Eurostat, 2015). Other western European countries landfilled considerably less waste in 2003. For example, Austria landfilled 30\%, Belgium 11\%, Denmark 7\%, Germany $20 \%$, the Netherlands $3 \%$ and Sweden $13 \%$. The EU average was $50 \%$. The reasons for the UK's high landfill rate can be seen in a range of factors. A lack of public interest, the availability of cheap landfill sites, limited collection services for recyclable materials and costs associated with recycling were just a few of the reasons for this (Morris, Phillips, \& Read, 1998; Price, 2001; Read, 1999; Read, Phillips, \& Robinson, 1997; Symanski, 1996). As a consequence, many materials which are easily recyclable ended up on landfill sites (Popplewell et al., 2006). However, this situation has changed as a result of EU-pressure, governmental regulations and education campaigns. Today, recyclables such as paper, plastic and glass are normally treated separately from the rest of the waste stream - which resulted in a recycling rate of over 44\% in 2013 (Department for Environment, Food and Rural Affairs [DEFRA], 2014). From 2015 onwards, separate collection for waste paper, metal, plastic and glass is mandatory under the Waste Regulations 2011. Relevant education campaigns in schools and elsewhere grew in number and scope (DEFRA, 2006; Waste Watch, 2015; Zhang, Williams, Kemp, \& Smith, 2011).

Nevertheless, compared with its European neighbours, the UK still relies heavily on landfill for the final disposal of household waste. In 2012, approximately $172 \mathrm{~kg}-$ around $35 \%$ - of municipal waste was landfilled per capita. In the same year, Belgium landfilled $5 \mathrm{~kg}$, Denmark - $17 \mathrm{~kg}$, Germany - $3 \mathrm{~kg}$, the Netherlands - $8 \mathrm{~kg}$, Norway $9 \mathrm{~kg}$ and Sweden $-3 \mathrm{~kg}$ per capita. The EU average was $160 \mathrm{~kg}$ per capita (Eurostat, 2015). Waste reduction - the best option to manage waste - is reflected in the national 
municipal waste production statistics, as can be seen in Figure 2. Between 2003 and 2012, the amount of waste produced per capita decreased from $591 \mathrm{~kg}$ in 2003 to 472 $\mathrm{kg}$ in 2012 (Eurostat, 2015). In 2012, the UK consequently produced less waste than the average EU citizen (who produced $488 \mathrm{~kg}$ ) but more than other EU members such as Belgium (456 kg), the Czech Republic (308 kg), Poland (314 kg) or Sweden (462 kg). Incineration with energy recovery is currently on the rise but this technology is still regarded sceptically by a large part of the population in the UK (Lima, 2004, 2006; United Kingdom Without Incineration Network (UKWIN), 2014).

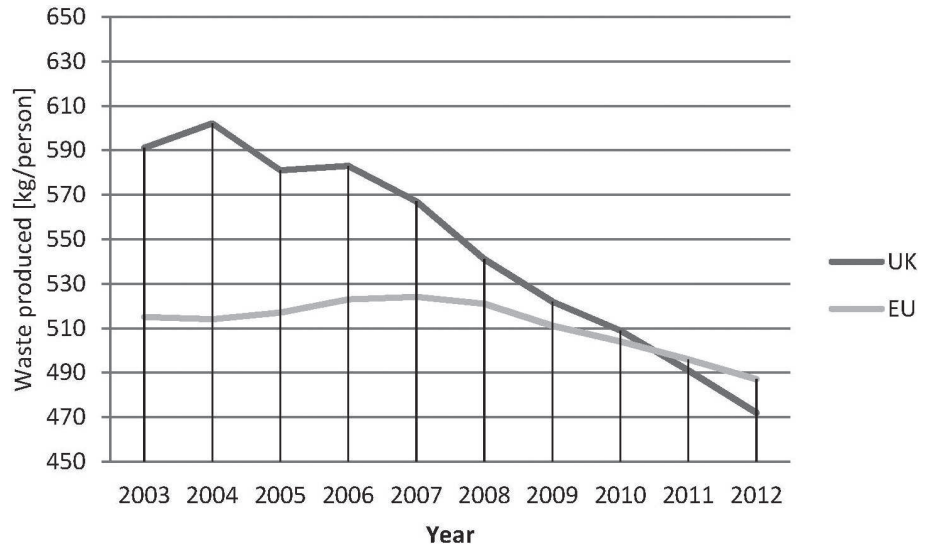

Figure 2. Waste production in kilogram per person between 2003 and 2012 in the UK and the EU (Eurostat, 2015)

\section{Research Aim}

Sustainable development is an important aim and needs to be strengthened. In the area of waste management, everybody can help to achieve a more sustainable future by producing as little waste as possible and by helping to recycle and compost as much waste as possible. Schools in particular can help to achieve this aim.

Until now, it has not been analysed in how far grammar school students differ from comprehensive school students in their knowledge, attitudes and behaviour in respect to waste management. In the current study, questionnaires were designed and distributed in a grammar and a comprehensive school in the same city of eastern England to find out what similarities and differences exist between the two student populations. It is of importance to find out what teachers in different school types can do to further promote sustainable development in the long run. The research aim of the current study is therefore to identify current weaknesses in the area of knowledge, attitudes and behaviour regarding waste management in a comprehensive and a grammar school. While appropriate waste management is a vast field and education on waste management cannot cover all potential aspects of this field, teachers should be able to be aware that some areas of waste management or some waste management options need particular attention.

The basis for the analysis is the waste hierarchy as is stipulated in the EU waste framework directive. Waste reduction is seen as superior to waste re-use, re-use as superior to recycling/composting, which is seen as superior to incineration with energy recovery. Landfill is seen as the worst option for managing waste. 


\section{Method}

To explore similarities and differences between students from a grammar and a comprehensive school in respect to knowledge, attitudes and behaviour regarding waste management, an explorative approach was chosen. In 2009, questionnaires were designed and piloted in different schools in England. Teachers in each of the schools where the questionnaire was tested were addressed regarding the questionnaire. Teachers crosschecked the language and the content of the questionnaire and were asked whether they considered the questions appropriate for the school type and the age of the questioned students.

After piloting the questionnaire, a range of questions were rephrased or changed completely to take into account the level of knowledge of the students. In general, students over the age of 11 understood the questions well. Younger students often had problems with some of the questions. The questionnaire was than distributed in two schools in the same city in England. The city is situated in the east of England and has a population of around 100,000. The city was chosen because teachers in both schools the comprehensive and the grammar school - were supportive of the research aim and agreed to participate in the questionnaire.

Obtaining information from multiple choice and open-ended questions on waste management, attitudes regarding waste management options and behaviour in the area of waste recycling were objectives of the questionnaire. Students were also asked where they gained their waste-related knowledge from.

Specifically, the part of the questionnaire which is analysed in this paper consisted of seven questions. Question 1: Below is a list of issues. Please tick the relevant box to indicate how much you know about the different issues. A list of concepts was provided. Students could choose between the answer options: I have never heard of it; I have heard of it but I don't know what it means and I have heard of it and I know what it means.

Question 2: Please indicate how important on a scale, you find the issues listed below $(10=$ very important and $1=$ not at all important $)$. Students were asked how important different waste related waste management options (reduce the amount of waste, recycle waste, compost organic waste and re-use waste) appear to them.

Question 3: Do you think we should reduce the amount of household waste or rubbish? If you think we should not reduce it, please tell us why. If you think we should reduce it, please also tell us why.

Question 4: If you do recycle, please tell us which materials you recycle and how often. Students could choose between "whenever possible"; "at least once every month"; "at least twice a year"; "almost never" and "other (please specify)". For the purpose of the analysis, "at least once every month" and "at least twice a year" were summarised as one category which is called "sometimes".

Question 5: A list of materials is provided below. Please circle the materials that can be recycled.

Question 6: If you know what incineration is, please tell us if you think that it is a good way of treating waste. The answer options were: Yes it is, because...; No, it isn't, because...; It can be if... and I don't know. Students could then explain their viewpoint.

Question 7: Where did you get your waste related knowledge from? A list of potential sources was provided.

Participating pupils were between 13 and 14 years of age. 110 students were surveyed in the grammar school and 143 in the comprehensive school. The questionnaires were 
filled out anonymously in class. The same researcher handed out the questionnaires in both schools on different days of the same month. The researcher highlighted that there are no right or wrong answers, that the questionnaire and the answers to the questions were completely anonymous and that copying of neighbours was therefore not necessary. Teachers were advised to not provide any help in cases where students were unsure about a question.

Quantitative and qualitative analyses were carried out. For the quantitative analysis, the statistical software package SPSS and Excel were used. Answers to multiple choice questions were analysed by providing cross-tabulation and calculating frequencies to allow direct comparison between the two student groups. Open-ended questions were grouped into categories so as to be able to compare them relatively easily. For instance, answer options such as Incineration is bad because it pollutes the air and Incineration is bad because it leads to exhaust gases were compiled in the section Incineration leads to air pollution. The answers were also compiled into categories by another researcher from the same department. In some cases, this researcher compiled the answers slightly differently and used more categories. Where there were discrepancies regarding categories, instead of combining them, more categories were created. Answers which were only given by one student were compiled under a specific section which is called Other.

\section{Results}

Question 1: Different waste-related concepts were provided, and students were asked whether they were aware of these concepts. The results can be seen in Table 1 . Overall, students from the grammar school were more likely to state that they "had heard about" the particular concepts and "knew what it meant", whereas comprehensive school students often stated that they had not heard of a concept or did not know what it meant. For instance, over $11 \%$ of the students from the comprehensive school had not heard about incineration and over $15 \%$ had never heard of landfill.

Table 1

Percentage of Students who had Heard of the Named Concepts, had not Heard of the Concepts or Knew what They Meant

\begin{tabular}{|c|c|c|c|c|c|c|c|c|}
\hline & \multicolumn{2}{|c|}{$\begin{array}{c}\text { Have never heard } \\
\text { of it }\end{array}$} & \multicolumn{2}{|c|}{$\begin{array}{c}\text { Have heard of it/ } \\
\text { don't know what } \\
\text { it means }\end{array}$} & \multicolumn{2}{|c|}{$\begin{array}{c}\text { Have heard of it/ } \\
\text { know what it } \\
\text { means }\end{array}$} & \multicolumn{2}{|c|}{$\begin{array}{l}\text { Missing } \\
\text { answer }\end{array}$} \\
\hline & 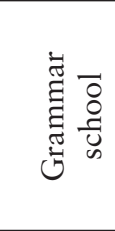 & 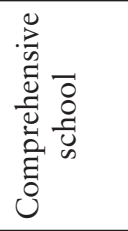 & 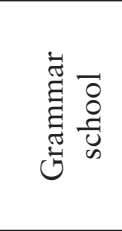 & 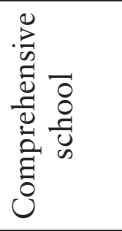 &  & 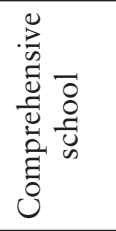 & 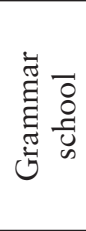 & 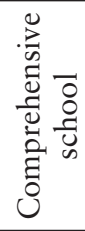 \\
\hline Recycling of paper & 0.0 & 3.5 & 0.9 & 1.4 & 99.1 & 95.1 & 0.0 & 0.0 \\
\hline Kerbside collection & 0.0 & 4.9 & 10.9 & 21.0 & 89.1 & 74.1 & 0.0 & 0.0 \\
\hline Composting & 0.0 & 5.6 & 1.8 & 18.9 & 98.2 & 74.8 & 0.0 & 0.7 \\
\hline Incineration & 0.9 & 11.2 & 19.1 & 26.6 & 80.0 & 61.5 & 0.0 & 0.7 \\
\hline Landfill & 1.8 & 15.4 & 13.6 & 24.5 & 84.6 & 59.4 & 0.0 & 0.7 \\
\hline
\end{tabular}


Question 2: Students were asked how important different waste management options appear to them on a scale from 1 to 10 . The arithmetic means (which are provided in Table 2) indicate that the order of importance (given in brackets) is the same between grammar and comprehensive school students. However, grammar school students rated all concepts as more important than the comprehensive school students.

Table 2

Mean Values of Importance of Waste Management Options, the Order of Importance is Shown in Brackets

\begin{tabular}{lcc}
\hline \multirow{2}{*}{ Concept } & \multicolumn{2}{c}{ Importance } \\
\cline { 2 - 3 } & Grammar school & Comprehensive school \\
\hline Reduce the amount of waste & $8.39(2)$ & $7.76(2)$ \\
\hline Recycle waste & $8.6(1)$ & $7.93(1)$ \\
\hline Compost organic waste & $7.58(4)$ & $6.18(4)$ \\
\hline Re-use waste & $7.97(3)$ & $6.91(3)$ \\
\hline
\end{tabular}

Question 3: When asked whether students thought that waste volumes should be reduced, all students in the grammar school and all students - except one - in the comprehensive school stated that waste should be reduced. The comprehensive school student that did not find a reduction of waste important stated that it would be "bad for recycling companies" whereas all the other students named primarily environmental reasons for the reduction. Limited landfill capacity, global warming and environmental pollution were the reasons most often named by both, grammar school students and comprehensive school students, for a reduction of waste. Around $10 \%$ of the grammar school students also named the saving of resources as a reason. This aspect was only named by $3.4 \%$ of the comprehensive school students. Overall, the answers given by the grammar school students and the comprehensive school students did not show large differences.

Question 4: When asked about recycling behaviour, there is a clear difference between grammar school students and comprehensive school students. The former recycled more often "whenever possible" while the later recycled "almost never" or left the answer blank, as can be seen in Table 3 .

Question 5: Asked about whether they knew which materials could be recycled, grammar school students more often classified materials correctly as recyclable, as can be seen in Table 4. Tetra Paks were the only material which was more often classified correctly by comprehensive school students compared to grammar school students. The same percentage of students in the grammar and the comprehensive school classified PET bottles correctly. 
Table 3

Percentage of Students who Stated that they Recycled Whenever Possible, Sometimes or Almost Never

\begin{tabular}{|c|c|c|c|c|c|c|c|c|}
\hline & \multicolumn{2}{|c|}{ Whenever possible } & \multicolumn{2}{|c|}{ Sometimes } & \multicolumn{2}{|c|}{ Almost never } & \multicolumn{2}{|c|}{ Missing answer } \\
\hline & 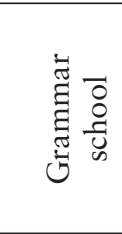 & 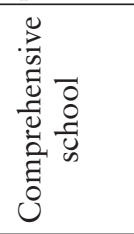 &  & 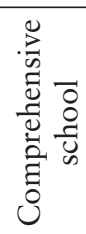 & 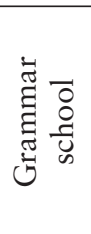 & 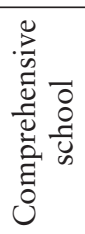 & 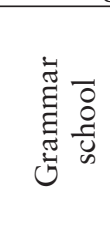 & 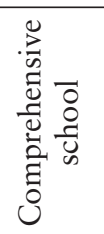 \\
\hline Paper & 88.2 & 70.6 & 10.9 & 10.5 & 0.9 & 4.9 & 0 & 14 \\
\hline Cans & 69.1 & 55.2 & 16.4 & 12.6 & 9.1 & 14.7 & 5.4 & 17.5 \\
\hline Glass bottles & 72.2 & 55.2 & 14.5 & 16.8 & 10.0 & 11.9 & 3.3 & 16.1 \\
\hline
\end{tabular}

Table 4

Percentage of Students who Classified the Named Materials Correctly as Recyclable

\begin{tabular}{lcc}
\hline \multirow{2}{*}{ Materials } & \multicolumn{2}{c}{ Correct answer (\%) } \\
\cline { 2 - 3 } & Grammar school & Comprehensive school \\
\hline Paper & 99 & 97 \\
\hline Glass & 97 & 80 \\
\hline Fruit juice cartons (Tetra Paks) & 46 & 54 \\
\hline Plastic bottles (PET bottles) & 84 & 84 \\
\hline Drink cans & 93 & 84 \\
\hline Cardboard & 96 & 91 \\
\hline Aluminium Foil & 44 & 36 \\
\hline
\end{tabular}

Question 6: Students were also asked whether they considered incineration as a good technology to treat waste, a potentially good technology to treat waste if certain criteria are met, not a good technology to treat waste, or whether they were unsure if incineration is a good technology for the treatment of waste. Students were also asked to provide reasons for their judgement.

The answers can be seen in Table 5. Grammar school students were more likely to have an opinion about incineration. They more often stated that it is not a good technology for the treatment of waste and were also more likely to consider it a potentially good technology if certain criteria are met. Students who thought that it could potentially be a good technology normally named the containment of fumes, the recovery of energy and the limitation of the technology to materials which cannot (easily) be recycled. Students who disapprove of incineration considered it harmful to human health and the environment.

Overall, students from the comprehensive school were more likely to have no opinion about incineration, either by ticking I do not know whether it is a good technology for the treatment of waste or by leaving the answer to the question blank. Over $50 \%$ of the students answered the question in this way. 
Table 5

Impression that the Students from the Grammar and the Comprehensive School had about Incineration

\begin{tabular}{lcc}
\hline & \multicolumn{2}{c}{ Answers (\%) } \\
\cline { 2 - 3 } & $\begin{array}{c}\text { Grammar } \\
\text { school }\end{array}$ & $\begin{array}{c}\text { Comprehensive } \\
\text { school }\end{array}$ \\
\hline A good technology for the treatment of waste & 5 & 7 \\
\hline Not a good technology for the treatment of waste & 44 & 29 \\
\hline A potentially good technology if certain criteria are met & 17 & 11 \\
\hline I do not know whether it is a good technology & 18 & 26 \\
\hline No answer given & 16 & 27 \\
\hline
\end{tabular}

Question 7: Finally, students were asked from where they gained their knowledge of waste related subjects. Around $80 \%$ of the students from the grammar school stated that they received their knowledge from school, compared to around $50 \%$ of the students from comprehensive school. Grammar school students were also more likely to receive their knowledge from their families. Around 90\% stated that this was one source of their information compared to $70 \%$ of the comprehensive school students. At the same time, grammar school students were also more likely to receive their information from friends $(40 \%$ compared to $20 \%$ ), magazines (25\% compared to $19 \%$ ), television $(83 \%$ compared to $68 \%$ ) and the Internet ( $44 \%$ compared to $25 \%$ ). Hence, they were overall more likely to receive information from the named sources and more likely to use different information resources.

\section{Discussion}

Overall, grammar school students had higher levels of knowledge and were more likely to recycle materials. They also rated different waste management options (reduction, re-use, recycling and composting) as being of higher importance compared to the students from the comprehensive school. However, the order of importance was the same between students from the grammar school and students from the comprehensive school. Both student groups considered recycling as most important, followed by waste reduction, re-use of waste and finally by composting. According to the waste hierarchy and national policy, waste reduction is the best option, followed by re-use and then recycling/composting. It should be easy to see that reduction is the most sustainable option: it leads to a maximising of resources and energy savings. It is therefore surprising that students did not rate it as the most important of the proposed options.

Interestingly, students do not feel that recycling and composting are equally important, although the treatment hierarchy sees these two approaches as being of equal importance. Both recycling and composting divert waste efficiently away from landfill. In the case of compostable materials, this is of particular environmental importance because organic fractions lead to the release of methane when put on landfill sites and thus exacerbates global warming. The students surveyed, however, clearly favoured recycling over composting, which might indicate a lack of knowledge regarding the lifecycle of organic fractions that end up on landfill sites.

In respect to students' attitudes regarding landfill, grammar school students and comprehensive school students were equally likely to dislike the technique for environ- 
mental reasons. Equally, almost all students from both schools stated that waste should be reduced for environmental or social reasons; this is in accordance with the waste hierarchy.

Incineration was overall regarded sceptically by the majority of the students. Grammar school students were more likely to voice their dislike for the technology or to connect it to factors such as energy recovery, filtration technologies or the limitation to materials which cannot (easily) be recycled. Students from the comprehensive school were more likely to have no opinion about incineration, illustrating the need for more specific information to be provided in comprehensive schools regarding this technology. In general, students should be aware that incineration is currently used and that it can help to reduce landfill volumes. However, students should also be aware that waste reduction, re-use, recycling and composting are more sustainable compared with incineration. Only if the advantages and disadvantages of incineration are known will students be able to judge the technology realistically. Around $50 \%$ of the comprehensive school students and over $35 \%$ of the grammar school students seem to lack this knowledge.

When it comes to recycling behaviour, grammar school students outperformed their counterparts from comprehensive school. They were more likely to recycle paper, glass and cans "whenever possible". Whether this is a result of higher levels of knowledge remains unclear. Family background, personal values and household infrastructure clearly also play a role, as has been shown by a range of researchers (Best \& Mayerl, 2013; Edgerton, McKechnie, \& Dunleavy, 2009; Kaciak \& Kushner, 2009).

Overall, grammar school students had higher levels of knowledge and showed a more environmentally friendly attitude compared to comprehensive school students. It can therefore be assumed that they are more environmentally concerned and better educated regarding waste management. Both might lead to them recycling more often. Comprehensive school students surprisingly often stated that they had not heard about some of the named waste management options or that they did not know what they meant. This lack of knowledge needs to be addressed at school since only knowledgeable students will make the right choices when it comes to waste management behaviour. Overall, comprehensive school students were less likely to receive their information from different sources such as their family, friends, television or the Internet. To compensate for these shortcomings, schools need to put particular emphasis on waste related issues. At the moment, only $50 \%$ of the comprehensive school students stated that they received their knowledge about waste management in school. In this area, comprehensive school teachers can clearly increase information flow by highlighting the benefits, needs and possibilities of waste management options on the regional, the national and the global level. While knowledge alone is not sufficient for behavioural changes, it is a necessary precondition. Equally, the large proportion of students who had no opinion about incineration should be addressed since it will lead to young adults that are unaware of the possible benefits and drawbacks of incineration technologies. They are therefore more prone to manipulation by pressure groups. In a country where incineration plants are currently widely used, built and also have much opposition, it is essential that students are aware of the possibilities (as well as the limitations of incineration) and that they are able to reflect rationally on this technology.

Education can help to minimise these shortcomings by providing neutral information on waste management options. While this might not necessarily enhance recycling beha- 
viour, it can help to increase the willingness to examine one's personal behaviour more thoroughly. Only if people are knowledgeable about waste management possibilities, such as composting, kerbside collection services or recycling, will they be able to participate in, or decide among these options.

Overall, the questionnaire also showed that the differences between grammar and comprehensive school students are primarily one of intensity, not of general attitude. Recycling is seen as very important by students from both schools. All students except one thought that waste should be reduced and most students stated that they recycled at least sometimes. These tendencies are clearly positive and illustrate that the basis on which a further improvement of environmental factors associated with waste management is possible. However, waste reduction was not judged as being the most important waste management approach. Instead, recycling was seen as more important by students of both school types. This is not in accordance with the waste management hierarchy and contrary to sustainable development. Equally, composting was rated as being of less importance than recycling, reduction and re-use, although composting is as important as recycling. Both technologies divert waste efficiently away from landfill. Teachers of both school types should therefore highlight the environmental benefits of waste reduction compared to waste recycling as well as the importance of composting, a technique which every student can relatively easily apply at home if knowledge on how to do it and to the motivation to do it exists.

\section{Conclusions and Future Research}

For the first time, the current study showed that there are differences between grammar school students' and comprehensive school students' knowledge, attitudes and behaviour regarding waste management. Grammar school students had higher levels of knowledge, considered different waste management options as more important, and were more likely to recycle their waste. The shortcomings of comprehensive school students need to be addressed by teachers of all disciplines to enhance the likeliness of these students to participate in recycling and composting schemes and to be able to make educated decisions regarding waste management options. Moreover, there is a need in both schools to highlight the importance of waste reduction and waste re-use compared to recycling. Waste reduction and waste re-use are the best options when it comes to waste management. Both approaches minimise the negative environmental impacts and poor resource use associated with waste. Communicating this to young people is essential to influence their lifestyle choices in the long run.

It will be necessary to find out why students considered waste reduction as less important than recycling. Possibly, the weight which is put on recycling has led some students to believe that waste reduction is no longer necessary. Alternatively, waste reduction might be seen as inconvenient compared to recycling. Future research should therefore address these questions and should try to identify educational options that can help to increase students' willingness to participate in pro-environmental waste management options. 


\section{References}

Ball, S. J., Bowe, R., \& Gewirtz, S. (1996). School choice, social class and distinction: The realization of social advantage in education. Journal of Education Policy, 11, 89-112.

Ballantyne, R., Fien, J., \& Packer, J. (2001). School environmental education programme impacts upon student and family learning: A case study analysis. Environmental Education Research, 7, 23-37.

Baud, I., Grafakos, S., Hordijk, M., \& Post, H. (2001). Quality of life and alliances in solid waste management: Contributions to urban sustainable development. Cities, 18, 3-12.

Best, H. \& Mayerl, J. (2013). Values, beliefs, attitudes: An empirical study on the structure of environmental concern and recycling participation. Social Science Quarterly, 94, 691-714.

Boliver, V., \& Swift, A. (2011). Do comprehensive schools reduce social mobility? The British Journal of Sociology, 62, 89-110.

Clifford, P., \& Heath, A. (1984). Selection does make a difference. Oxford Review of Education, 10, 85-97.

Cribb, J., Jesson, D., Sibieta, L., Skipp, A., \& Vignoles, A. (2013). Poor grammar: Entry into grammar schools for disadvantaged pupils in England. London: The Sutton Trust.

Crozier, G., Reay, D., James, D., Jamieson, F., Beedell, P., Hollingworth, S. \& Williams, K. (2008). White middle-class parents, identities, educational choice and the urban comprehensive school: Dilemmas, ambivalence and moral ambiguity. British Journal of Sociology of Education, 29, 261-272.

Department for Environment, Food and Rural Affairs (DEFRA). (2006). Evaluation of the household waste incentives pilot scheme (Rep. No. AEAT/ED51362/Issue 1).

Department for Environment, Food and Rural Affairs (DEFRA). (2014). Statistics on waste managed by local authorities in England in 2013-2014. Retrieved January 17, 2015, from https://www.gov.uk/government/uploads/system/uploads/ attachment_data/file/375945/Statistics_Notice_Nov_2014_Final_3_.pdf

Edgerton, E., McKechnie, J., \& Dunleavy, K. (2009). Behavioral determinants of household participation in a home composting scheme. Environment and Behavior, 41, 151-169.

European Commission (EC). (1996). Cost-benefit analysis of the different municipal solid waste management systems: Objectives and instruments for the year 2000. Luxembourg: European Community.

European Commission (EC). (2011). Sustainable development in the European Union. 2011 monitoring report of the EU sustainable development strategy. Luxembourg: Publications Office of the European Union.

European Commission (EC). (2012). Guidance on the interpretation of key provisions of directive 2008/98/EC on waste. Brussels: Directorate-General Environment.

European Parliament and European Council. (2008). Directive 2008/98/EC on waste (Waste Framework Directive). Retrieved December 12, 2014, from ec.europa.eu/ environment/waste/framework/

Eurostat. (2015). Municipal waste. Retrieved January 1, 2015, from http://epp.eurostat. ec.europa.eu/portal/page/portal/waste/data/database 
Farmer, J., Knapp, D., \& Benton, G. M. (2007). An elementary school environmental education field trip: Long-term effects on ecological and environmental knowledge and attitude development. The Journal of Environmental Education, $38,33-42$.

Gordon, P., \& Lawton, D. (2003). Dictionary of British education. London: Woburn Press.

Gross, P. M. (1977). An analysis of attitudes, knowledge, and perceptions of elementary school students following participation in a special environmental education program (Unpublished doctoral dissertation). The University of Iowa, Iowa, the United States of America.

Hanushek, E. A., \& Woessmann, L. (2006). Does educational tracking affect performance and inequality? Differences-in-differences evidence across countries. The Economic Journal, 116, C63-C76.

Harris, R. \& Rose, S. (2013). Who benefits from grammar schools? A case study of Buckinghamshire, England. Oxford Review of Education, 39, 151-171.

Iannelli, C. (2013). The role of the school curriculum in social mobility. British Journal of Sociology of Education, 34, 907-928.

Kaciak, E. \& Kushner, J. (2009). Determinants of residents' recycling behaviour. International Business \& Economics Research Journal, 8, 1-12.

Lima, M. L. (2004). On the influence of risk perception on mental health: Living near an incinerator. Journal of Environmental Psychology, 24, 71-84.

Lima, M. L. (2006). Predictors of attitudes towards the construction of a waste incinerator: Two case studies. Journal of Applied Social Psychology, 36, 441-466.

Manning, A., \& Pischke, J. S. (2006). Comprehensive versus selective schooling in England and Wales: What do we know? London: Centre for the Economics of Education.

Morris, J. R., Phillips, P. S., \& Read, A. D. (1998). The UK landfill tax: An analysis of its contribution to sustainable waste management. Resources, Conservation and Recycling, 23, 259-270.

Morrissey, A. J., \& Browne, J. (2004). Waste management models and their application to sustainable waste management. Waste Management, 24, 297-308.

Oakland, J. (1993). A dictionary of British institutions: A students' guide. London: Routledge Chapman \& Hall.

Pires, A., Martinho, G., \& Chang, N. B. (2011). Solid waste management in European countries: A review of systems analysis techniques. Journal of Environmental Management, 92, 1033-1050.

Popplewell, M., Gostick, J., Mills, P., Cleghorn, D., Marks, H., Munro, A., ... Moorton, E. (2006). Reducing the reliance of landfill in England. London: Department for Environment, Food and Rural Affairs.

Price, J. L. (2001). The landfill directive and the challenge ahead: Demands and pressures on the UK householder. Resources, Conservation and Recycling, 32, 333-348.

Read, A. D. (1999). A weekly doorstep recycling collection, I had no idea we could!: Overcoming the local barriers to participation. Resources, Conservation and Recycling, 26, 217-249.

Read, A. D., Phillips, P., \& Robinson, G. (1997). Landfill as a future waste management option in England: The view of landfill operators. Resources, Conservation and Recycling, 20, 183-205. 
Schmidt, J. H., Holm, P., Merrild, A., \& Christensen, P. (2007). Life cycle assessment of the waste hierarchy - a Danish case study on waste paper. Waste Management, 27, 1519-1530.

Steedman, J. (2012). Longitudinal survey research into progress in secondary schools, based on the national child development study. In G. Walford (Ed.), Doing sociology of education (pp. 177-206). Oxon, New York: Routledge.

Sullivan, A., Parsons, S., Wiggins, R., Heath, A., \& Green, F. (2014). Social origins, school type and higher education destinations. Oxford Review of Education, 40, 739-763.

Symanski, S. (1996). The impact of compulsory competitive tendering on refuse collection services. Fiscal Studies, 17, 1-19.

The Sutton Trust. (2005). Rates of eligibility for free school meals at the top state schools. Retrieved January 17, 2015, from http://www.suttontrust.com/wp-content/ uploads/2005/10/1RatesOfEligibilityforFreeSchoolMealsattheTopStateSchools.pdf

United Kingdom Without Incineration Network (UKWIN). (2014). Incinerators in the UK. Retrieved January 20, 2015, from http://ukwin.org.uk/

Walford, G. (1994). A return to selection? Westminster Studies in Education, 17, 1930 .

Waste Watch. (2015). Recyclezone: Education resources from waste watch. Retrieved January 17, 2015, from http://www.recyclezone.org.uk/home_iz.aspx.html

Wilson, D. C. (1996). Stick or carrot?: The use of policy measures to move waste management up the hierarchy. Waste Management \&o Research, 14, 385-398.

Zhang, N., Williams, I. D., Kemp, S., \& Smith, N. F. (2011). Greening academia: Developing sustainable waste management at Higher Education Institutions. Waste Management, 31, 1606-1616.

Correspondence concerning this paper should be addressed to Karin Dorina Kolbe, a PhD candidate, University of Koblenz and Landau, Campus Koblenz, ZFUW, Universitaetsstrasse 1, 56070 Koblenz, Germany. Email: karinkolbe@uni-koblenz.de 